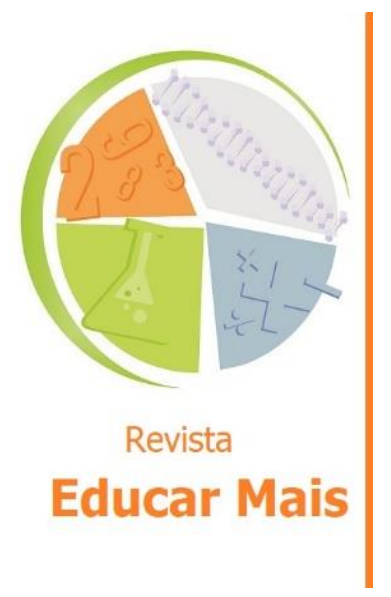

\title{
Ensino da Geometria nos anos finais do Ensino Fundamental: um problema sistêmico
}

\author{
Teaching Geometry in final years in Elementary Education: a sistemic \\ problem
}

\section{Enseñanza de Geometría en los últimos años en Educación Primaria: un problema sistémico}

Débora de Sales Fontoura da Silva Frantz ${ }^{1}$; ; Vanilde Bisognin² ${ }^{(\mathbb{D})}$

\section{RESUMO}

O presente artigo é uma pesquisa bibliográfica cujo objetivo consiste em investigar alguns fatores que nos permitam enxergar as dificuldades apresentadas no ensino de geometria no Ensino Fundamental como um problema sistêmico. Para tanto, buscamos informações nos documentos do Programme for International Student Assessment - PISA, bem como em relatórios fornecidos pelo Inep, dos quais mostraremos os resultados do desempenho médio em Matemática e os níveis de proficiência de alunos participantes do Brasil e da OCDE (Organização para a Cooperação e Desenvolvimento Econômico) e o desempenho desses alunos na categoria de conteúdo, espaço e forma, na disciplina de Matemática. Esses resultados representam indicativos que nos permitem deduzir que não é de hoje os obstáculos no ensino de geometria no Ensino Fundamental, pois não é somente um problema citado por alguns docentes de forma isolada, mas, sim, é um problema típico do mundo em que vivemos.

Palavras-chave: Pesquisa; Educação Matemática; PISA; Desempenho.

\begin{abstract}
This article is a bibliographical research whose objective is to investigate some factors that allow us to see the difficulties presented in the teaching of geometry in elementary school as a systemic problem. To do so, we searched for information in the documents of the Program for International Student Assessment - PISA, as well as in reports provided by Inep, of which we will show average performance results in Mathematics and the proficiency levels of participating students from Brazil and the OECD (Organization for the Economic Cooperation and Development) and the performance of these students in the category of content, space and form, in the subject of Mathematics. These results represent indicatives that allow us to deduce that the obstacles in the teaching of geometry in Elementary School are not new, as it is not only a problem mentioned by some teachers in isolation, but it is a typical problem in the world in which we live.
\end{abstract}

Keywords: Search; Mathematics Education; PISA; Performance.

\section{RESUMEN}

Este artículo es una investigación bibliográfica cuyo objetivo es investigar algunos factores que nos permiten ver las dificultades presentada em la enseñanza de la geometría en la escuela primaria como un problema sistémico. Para ello, buscamos información en los documentos del Programa de Evaluación Internacional de

\footnotetext{
${ }^{1}$ Licenciada em Matemática, Mestra em ensino de Matemática e Doutoranda em Ensino de Ciências e Matemática pela Universidade Franciscana (UFN), Santa Maria/RS - Brasil. E-mail: debora_frantz@hotmail.com

${ }^{2}$ Licenciada em Matemática, Mestra e Doutora em Matemática e Professora titular da Universidade Franciscana (UFN), Santa Maria/RS - Brasil. E-mail: vanilde@ufn.edu.br
} 
Alumnos - PISA, así como en los informes proporcionados por el Inep, del cual mostraremos los resultados del desempeño medio en Matemáticas y los niveles de competencia de los estudiantes participantes de Brasil y la OCDE. (Organización para la Cooperación y el Desarrollo Económicos) y el desempeño de estos estudiantes en la categoría de contenido, espacio y forma, en la asignatura de Matemáticas. Estos resultados representar indicativos que permiten deducir que no es nuevo los obstáculos en la enseñanza de la geometría en la escuela primaria no son nuevos, ya que no solo es un problema mencionado por algunos docentes de manera aislada, sino que es un problema típico del mundo en el que vivimos.

Palabras clave: Buscar; Educación Matemática; PISA; Rendimiento.

\section{INTRODUÇÃO}

Para entender a importância da problemática proposta nesta pesquisa acerca do ensino da geometria no Ensino Fundamental como um problema sistêmico, convém aqui destacar que, acima de tudo, essa é uma das categorias de conteúdos matemáticos que merece muito a nossa atenção, pois sua relevância aparece como uma dificuldade típica do mundo em que vivemos.

Mas, antes de tudo, é considerável elucidar a seguinte pergunta: como esse assunto veio à tona neste projeto de pesquisa? Como resposta, ressalta-se que essa temática veio à lume neste projeto a partir do momento em que tivemos o primeiro contato com quatro docentes que ministram a disciplina de Matemática para alunos do Ensino Fundamental em quatro escolas distintas da rede municipal de ensino, do município de Santa Cruz do Sul - RS, e que concordaram em participar dessa investigação de forma voluntária na aplicação do nosso artefato pedagógico. Esses docentes foram questionados acerca de uma problemática que os angustie, ou seja, algum conteúdo que os mesmos apresentam ou percebam mais dificuldade em transmitir aos seus alunos. Como resposta quase que unânime, a Geometria foi citada como a mais complexa e a que eles apresentam maior dificuldade para transmitir aos seus alunos, bem como para estabelecer conexões de conteúdos Matemáticos com esse conteúdo, pois, conforme relato desses docentes, muitos alunos não conseguem fazer relação do que estão estudando com os conhecimentos que eles possuem.

No entanto, nos questionamos: será que essa problemática citada pelos docentes de Matemática participantes é um problema sistêmico? Destacamos primeiramente que, sistêmico, deriva da palavra sistema, que é o conjunto que forma determinado grupo, e sistêmico são todas as interligações necessárias que permitem enxergar o sistema como um todo, de uma forma mais ampla, desde os fatores críticos que favorecem até aqueles que podem ser considerados uma ameaça ao sistema e comprometer determinado grupo. No caso deste projeto, o que angústia os docentes participantes é a dificuldade de transmitir o conteúdo de geometria aos seus alunos e estabelecer conexões de conteúdos matemáticos com esse tema, de forma a fazer relações com o que é estudado com o conhecimento que os mesmos já possuem. Então, cabe a nós tentar aqui investigar e relatar alguns fatores que nos permitiram enxergar que essa problemática apresentada pelos docentes está muito além de ser apenas um problema isolado de um único docente, e, sim, ser um problema que vem ocorrendo com mais docentes, com mais escolas, com mais municípios, com mais estados e também com mais países, obtendo, assim, uma visão de diversos elementos e interações que interligam o sistema de ensino da geometria com a dificuldade apresentada, para que seja possível ocorrer mudanças.

Para tanto, optamos em buscar informações nos documentos do Programme for International Student Assessment (Pisa), bem como em relatórios fornecidos pelo Inep, com informações relativas às 
aplicações ocorridas nas últimas edições (2018, 2015 e 2012), das quais iremos mostrar os resultados do desempenho médio em Matemática de alunos participantes, bem como os níveis de proficiência, pontuação mínima e porcentagem de alunos participantes do Brasil e da OCDE³ (Organização para a Cooperação e Desenvolvimento Econômico) em cada nível. Além disso, destacaremos o resultado dos alunos brasileiros participantes no estado do Rio Grande do Sul na avaliação de Matemática por nível de proficiência e a pontuação média por dependência administrativa (Municipal e estadual) em relação à média do Brasil e da OCDE, bem como o desempenho desses alunos na categoria de conteúdo, espaço e forma, na disciplina de matemática.

Contudo, buscaremos relatar o que esclarecem os Parâmetros Nacional Curriculares (PCNs) (BRASIL, 1998) e a Base Nacional Comum Curricular (BNCC) ${ }^{4}$ (BRASIL, 2017) acerca dessa categoria de conteúdo. Também mostraremos o que relatam os autores Lorenzatto $(1995,2015)$ e Pavanello $(1993,1989)$ acerca dessa problemática relatada pelos docentes participantes, visto que os mesmos desenvolveram pesquisas associadas ao ensino da geometria na escola e o seu abandono.

\section{DESEMPENHO DO BRASIL NO PISA}

Antes de iniciar, cabe aqui ressaltar que a intenção da pesquisa não infere no debate da validade dessas avaliações, uma vez que elas não trazem de forma isolada apenas o desempenho dos alunos no ramo da Geometria, mas, sim, evidencia os resultados de maneira ampla na disciplina de Matemática.

Dessa forma, destacamos que os resultados divulgados da última edição do Pisa 2018, nomeado no Brasil de Programa de Avaliação Internacional de Estudantes, soou como um alerta de que ainda persistem grandes desafios para a educação básica do Brasil. O Pisa "visa avaliar a capacidade que os alunos de 15 anos de diferentes países/economias têm para mobilizar conhecimentos nos domínios da matemática, da leitura e das ciências e responder a situações comuns da vida quotidiana" (PORTUGAL, 2013, p. 1). O documento de avaliação, Brasil no Pisa, é realizado a cada três anos pela Organização para a Cooperação e Desenvolvimento Econômico (OCDE) e contém informações sobre o desempenho e a aprendizagem de alunos de 15 anos de idade, pelo fato destes estudantes estarem perto de concluir sua educação básica e possuírem os requisitos educacionais básicos à avaliação. Nas edições anteriores do Pisa, participavam da avaliação alunos matriculados a partir da $7^{a}$ série/80 ano, porém, com a ampliação do Ensino Fundamental para nove anos de duração (Lei nº 11.274, de 6 de fevereiro de 2006), todos os alunos elegíveis e matriculados a partir do 70 ano foram incluídos no PISA, pois, segundo dados apresentados nesse documento de avaliação, no Brasil, "houve um aumento no percentual da população de 15 anos de idade matriculada na escola a partir do 70 ano

\footnotetext{
${ }^{3}$ A OCDE (Organização para a Cooperação e Desenvolvimento Econômico) também atua no setor educacional e o seu principal órgão é o Comitê de Políticas Educacionais (Education Policy Committe). O órgão foi criado no ano de 2007, a fim de coordenar as ações que permeiam a educação, contribuindo para que os países consigam promover políticas públicas que garantam uma educação de qualidade. Disponível em: <https://mundoeducacao.uol.com.br/geografia/ocde.htm>. Acesso em: 22 jan. 2021.

4 A BNCC (Base Nacional Comum Curricular) é um documento de caráter normativo que define o conjunto orgânico e progressivo de aprendizagens essenciais que todos os alunos devem desenvolver ao longo das etapas e modalidades da Educação Básica, de modo que tenham assegurados seus direitos de aprendizagem e desenvolvimento, em conformidade com o que preceitua o Plano Nacional de Educação (PNE). Este documento normativo aplica-se exclusivamente à educação escolar, tal como a define o $\S 1^{\circ}$ do artigo $1^{\circ}$ da Lei de Diretrizes e Bases da Educação Nacional (LDB, lei n 9394/1996), e está orientado pelos princípios éticos, políticos e estéticos que visam à formação humana integral e à construção de uma sociedade justa, democrática e inclusiva, como fundamentado nas Diretrizes Curriculares Nacionais de Educação Básica (DCN). (BRASIL, 2017, p.7)
} 
do Ensino Fundamental, passando de 68\% em 2003 para 93\% em 2018" (Brasil no pisa, 2018, p. 43). Essa constatação revela uma realidade enfrentada por muitos professores que estão dentro das salas de aula, que a distorção (ano de ensino x idade), conforme consta na revista Nova Escola5, "no Brasil, pelo fato de termos uma distorção idade-série bastante grande nos resultados, isso faz com que vejamos como está uma determinada geração de estudantes, mas sem um foco específico na série".

Segundo o Anuário Brasileiro de Educação Básica de (2019, p. 74), o Pisa passou a ser, no ano 2000, quando seus resultados foram divulgados pela primeira vez, a principal referência internacional em avaliação de qualidade em Educação. No entanto, quem coordena a aplicação do Pisa no Brasil é o Instituto Nacional de Estudos e Pesquisas Educacionais Anísio Teixeira (Inep) e, segundo o Relatório Brasil no PISA (2018-2019, p. 20), o estudo realizado pelo Pisa "permite ao Brasil aferir conhecimentos e habilidades dos estudantes (...), pois o desafio é refletir a situação de instituições públicas e privadas, estados, regiões e estudantes com diferentes níveis socioeconômicos" (REVISTA NOVA ESCOLA ${ }^{6}$, 2018). No PISA 2018 são apresentados os resultados do desempenho de alunos dos 37 países membros da OCDE, além de 42 países/economias parceiras, totalizando 78 países participantes no Pisa 2018. A pontuação média, no caso particular da Matemática, nos países da OCDE, foi de 489 pontos e os alunos brasileiros que participaram dessa avaliação ficaram nas últimas posições nessa edição, ocupando a $70^{\mathrm{a}}$ colocação, com média de desempenho de 384 pontos, média essa bem inferior a da OCDE, conforme podemos observar na Figura 1, abaixo.

A Figura 1 apresenta o mapa mundi e a lista dos 78 países participantes do Pisa 2018, ordenada por ordem crescente de acordo com a pontuação média alcançada. O mapa foi pintado pela pesquisadora e dividido com 4 cores, de acordo com a diferença das pontuações médias do ranking mundial de desempenho dos alunos na avalição de Matemática de cada país em relação à pontuação média da OCDE. As cores verde, escuro e verde-claro destacam os países que ficaram com média superior a da OCDE, e as cores laranja e vermelho destacam os países que ficaram com média inferior a da OCDE. Inicialmente, dividiu-se os países em 3 grupos, os com média abaixo de 400 pontos, os com média entre 400 e 500 pontos e os com média acima de 500 pontos. No entanto, como a média da OCDE é 489 pontos, neste caso, os grupos de países que tiveram médias entre 400 e 500 pontos foram subdivididos em dois grupos, os países que foram pintados na cor verde-claro são os que ficaram com média acima da $O C D E$, porém, são médias que não são significativamente muito diferentes da média da $\mathrm{OCDE}$, e os países que foram pintados na cor laranja são os que ficaram com média abaixo da estipulada pela OCDE. Entretanto, são médias que não são muito diferentes da determinada pela OCDE. Já os países pintados na cor verde-escuro são os que agregaram pontuações médias significativamente bem superiores à média da $\mathrm{OCDE}$, acima de 500 pontos, e, por fim, os países que foram pintados na cor vermelho são os que obtiveram pontuações significativamente muito inferior da média da OCDE.

\footnotetext{
${ }^{5}$ Revista Nova Escola, citação de Wolney Cândido de Melo, professor de Física e pesquisador do Grupo de Estudos e Pesquisas em Avaliação Educacional (Gepave) da Faculdade de Educação da Universidade de São Paulo. Disponível em: <https://novaescola.org.br/conteudo/18738/pisa-2018-como-os-resultados-podem-contribuir-para-a-melhoria-daeducacao-no-brasil>. Acesso em: 28 jan. 2021.

6 Artigo da Revista Nova Escola. Disponível em: <https://novaescola.org.br/conteudo/18738/pisa-2018-como-osresultados-podem-contribuir-para-a-melhoria-da-educacao-no-brasil>. Acesso em: 28 jan. 2021.
} 
FIGURA 1 - Posição e pontuação média dos países participantes do ranking mundial em Matemática no PISA 2018.

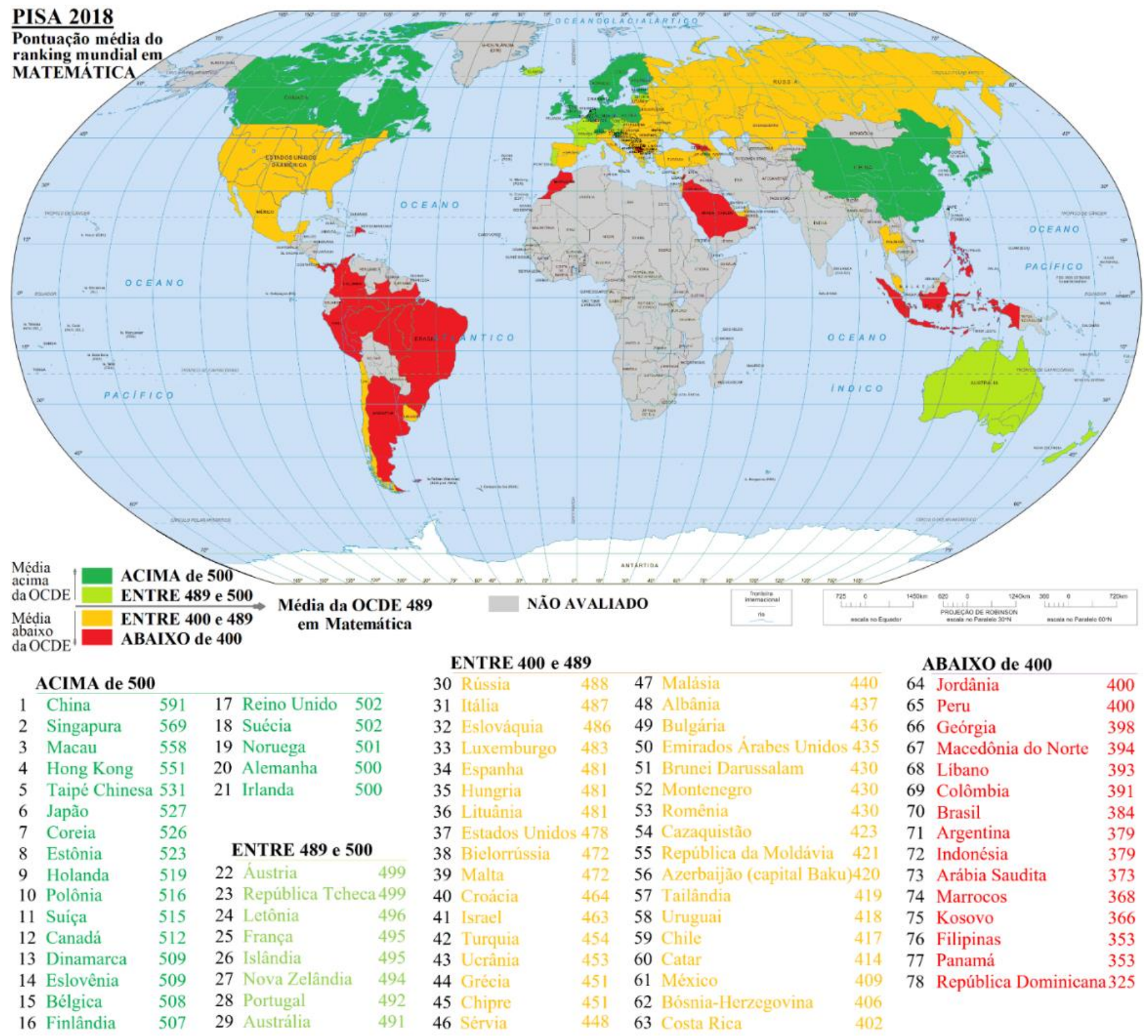

Fonte: Elaborada e editada pela autora, com base em dados da OCDE e PISA (2018) e no Mapa-múndi político com a identificação dos países do IBGE. Disponível em:

<https://atlasescolar.ibge.gov.br/images/atlas/mapas_mundo/mundo_planisferio_politico_a3.pdf >. Acesso em: 28 jan. 2021.

Como podemos observar na Figura 1, dentre os países pintados na cor verde-escuro, a China lidera o ranking em primeiro lugar, com média de 591 pontos. Já na América do Sul, todos os países participantes ficaram com médias abaixo da média da OCDE, e estão destacados no mapa nas cores laranja e vermelho. O país mais bem colocado na categoria Matemática é o Uruguai, com 418 pontos, aparecendo na $58^{a}$ posição do ranking geral, seguido de Chile, com 417 pontos e na 59a posição, e Costa Rica, com 402 pontos, na 63a posição.

O Brasil, destacado na cor vermelha, aparece nas últimas posições, ocupando a $70^{a}$ posição, com uma pontuação média de 384 pontos, superando apenas a Argentina, com 379 pontos, na 71a posição, e o Panamá, com 353 pontos, na 77a posição do ranking geral. Mas, apesar de o Brasil estar entre os piores colocados, ainda está à frente de outros países na disciplina avaliada, como Indonésia, Arábia Saudita, Marrocos, Kosovo, Filipinas e República Dominicana. Na avaliação do Pisa, os alunos são distribuídos em 6 (seis) níveis de proficiência em cada uma das 3 (três) áreas avaliadas (Leitura, 
Matemática e Ciências). A porcentagem de alunos em cada país que alcançam bons níveis de proficiência indica quão bem esses países conseguem favorecer a sublimidade em seus sistemas educativos. Os níveis mais elevados são o 5 e 0 6, onde se encontram os alunos com melhor desempenho. O nível 2 é considerado, segundo a OCDE, "o nível básico de proficiência que se espera de todos os jovens, a fim de que possam tirar proveito de novas oportunidades de aprendizagem e participar plenamente da vida social, econômica e cívica da sociedade moderna em um mundo globalizado" (OCDE, 2019b). Contudo, esse é o nível mínimo adequado para a plena participação na vida social, econômica e civil, sendo que os alunos que estão abaixo desse nível 2 são considerados com baixo desempenho na avaliação, conforme podemos observar na Tabela 1, onde estão descritos os seis níveis de proficiência em Matemática considerados no PISA 2018, bem como a pontuação mínima e a porcentagem de alunos participantes do Brasil e da OCDE em cada nível.

Tabela 1 - Descrição dos níveis de proficiência em Matemática, pontuação mínima e porcentagem de alunos participantes do Brasil e da OCDE em cada nível - Pisa 2018.

\begin{tabular}{|c|c|c|c|}
\hline NÍVEL & $\begin{array}{l}\text { PONTUAÇÃO } \\
\text { MÍNIMA }\end{array}$ & $\begin{array}{l}\text { PORCENTAGEM DE } \\
\text { ALUNOS NO NÍVEL }\end{array}$ & CARACTERÍSTICAS DAS TAREFAS \\
\hline 6 & 669 & $\begin{array}{l}\text { OCDE: } 2,4 \% \\
\text { Brasil: } 0,1 \%\end{array}$ & $\begin{array}{l}\text { No Nível 6, os estudantes são capazes de conceituar, } \\
\text { generalizar e utilizar informações com base em suas } \\
\text { investigações e na modelagem de problemas } \\
\text { complexos, e são capazes de usar seu conhecimento } \\
\text { em contextos relativamente não padronizados. } \\
\text { Conseguem estabelecer ligações entre diferentes } \\
\text { fontes de informação e representações e transitar } \\
\text { entre elas com flexibilidade. Evidenciam um } \\
\text { pensamento e um raciocínio matemáticos avançados. } \\
\text { São capazes de associar sua percepção e sua } \\
\text { compreensão junto com um domínio de operações e } \\
\text { relações matemáticas simbólicas e formais para } \\
\text { desenvolver novas abordagens e estratégias que lhes } \\
\text { permitam lidar com situações novas. Conseguem } \\
\text { refletir sobre suas ações e formular e comunicar com } \\
\text { precisão suas ações e reflexões, relacionadas às } \\
\text { constatações, interpretações e argumentações que } \\
\text { elaboram. São, ainda, capazes de explicar por que } \\
\text { razão estas são adequadas à situação original. }\end{array}$ \\
\hline 5 & 607 & $\begin{array}{l}\text { OCDE: } 8,5 \% \\
\text { Brasil: } 0,8 \%\end{array}$ & $\begin{array}{l}\text { No Nível 5, os estudantes são capazes de } \\
\text { desenvolver modelos para situações complexas e } \\
\text { trabalhar com eles, identificando restrições e } \\
\text { especificando hipóteses. Conseguem selecionar, } \\
\text { comparar e avaliar estratégias adequadas de } \\
\text { resolução de problemas para lidar com problemas } \\
\text { complexos relacionados a esses modelos. Conseguem } \\
\text { trabalhar estrategicamente, utilizando um vasto e } \\
\text { bem desenvolvido conjunto de habilidades de } \\
\text { pensamento e de raciocínio, representações } \\
\text { conectadas de maneira adequada, caracterizações } \\
\text { simbólicas e formais, e percepção relativa a essas } \\
\text { situações. Começam a refletir sobre suas ações e são } \\
\text { capazes de formular e de comunicar suas } \\
\text { interpretações e raciocínios. }\end{array}$ \\
\hline 4 & 545 & $\begin{array}{c}\text { OCDE: } 18,5 \% \\
\text { Brasil: } 3,4 \%\end{array}$ & $\begin{array}{l}\text { No Nível 4, os estudantes são capazes de trabalhar } \\
\text { de maneira eficaz com modelos explícitos em } \\
\text { situações concretas complexas, que podem envolver } \\
\text { restrições ou exigir formulação de hipóteses. São } \\
\text { capazes de selecionar e de integrar diferentes }\end{array}$ \\
\hline
\end{tabular}




\begin{tabular}{|c|c|c|c|}
\hline & & & $\begin{array}{l}\text { representações, inclusive representações simbólicas, } \\
\text { relacionando-as diretamente a aspectos de situações } \\
\text { da vida real. Conseguem utilizar seu conjunto limitado } \\
\text { de habilidades e raciocinar com alguma perspicácia } \\
\text { em contextos diretos. São capazes de construir e de } \\
\text { comunicar explicações e argumentos com base em } \\
\text { suas interpretações, argumentos e ações. }\end{array}$ \\
\hline 3 & 482 & $\begin{array}{l}\text { OCDE: } 24,4 \% \\
\text { Brasil: } 9,3 \%\end{array}$ & $\begin{array}{l}\text { No Nível 3, os estudantes são capazes de executar } \\
\text { procedimentos descritos com clareza, inclusive } \\
\text { aqueles que exigem decisões sequenciais. Suas } \\
\text { interpretações são seguras o suficiente para servirem } \\
\text { de base à construção de um modelo simples ou à } \\
\text { seleção e aplicação de estratégias simples de } \\
\text { resolução de problemas. São capazes de interpretar e } \\
\text { de utilizar representações baseadas em diferentes } \\
\text { fontes de informação e de raciocinar diretamente com } \\
\text { base nelas. Demonstram alguma capacidade para } \\
\text { lidar com porcentagens, frações e números decimais } \\
\text { e para trabalhar com relações de proporcionalidade. } \\
\text { Suas soluções indicam que eles se envolvem em } \\
\text { interpretações e raciocínios básicos. }\end{array}$ \\
\hline 2 & 420 & $\begin{array}{l}\text { OCDE: } 22,2 \% \\
\text { Brasil: } 18,2 \%\end{array}$ & $\begin{array}{l}\text { No Nível 2, os estudantes são capazes de interpretar } \\
\text { e reconhecer situações em contextos que não exigem } \\
\text { mais do que inferências diretas. Conseguem extrair } \\
\text { informações relevantes de uma única fonte e utilizar } \\
\text { um único modo de representação. Conseguem } \\
\text { empregar algoritmos, fórmulas, procedimentos ou } \\
\text { convenções básicas para resolver problemas que } \\
\text { envolvem números inteiros. São capazes de fazer } \\
\text { interpretações literais de resultados. }\end{array}$ \\
\hline 1 & 358 & $\begin{array}{l}\text { OCDE: } 14,8 \% \\
\text { Brasil: } 27,1 \%\end{array}$ & $\begin{array}{l}\text { No Nível 1, os estudantes são capazes de responder } \\
\text { a questões que envolvam contextos familiares, nas } \\
\text { quais todas as informações relevantes estão } \\
\text { presentes e as questões estão claramente definidas. } \\
\text { Conseguem identificar informações e executar } \\
\text { procedimentos rotineiros, de acordo com instruções } \\
\text { diretas, em situações explícitas. Conseguem realizar } \\
\text { ações que são, quase sempre, óbvias e que decorrem } \\
\text { diretamente dos estímulos dados. }\end{array}$ \\
\hline $\begin{array}{l}\text { Abaixo } \\
\text { de } 1\end{array}$ & & $\begin{array}{l}\text { OCDE: } 9,1 \% \\
\text { Brasil: } 41,0 \%\end{array}$ & $\begin{array}{l}\text { No Nível Abaixo de 1, a OCDE não especifica as } \\
\text { habilidades desenvolvidas. }\end{array}$ \\
\hline
\end{tabular}

Fonte: Elaborado pela autora, com base em dados da Daeb/Inep e da OCDE.

É possível observar na porcentagem de alunos por nível de proficiência em Matemática, na Tabela 1, que aproximadamente $31,8 \%$ dos alunos alcançaram pelo menos o nível 2 ou acima desse nível de proficiência em Matemática, porcentagem essa que é bem distante da média da OCDE, que é $76 \%$. O nível 2, que é considerado pela OCDE como básico, somente é atingido a partir da pontuação média de 420 pontos de desempenho na avalição em Matemática no Pisa. Como os alunos brasileiros não obtiveram mais do que 384 pontos, o Brasil, neste caso, fica classificado no nível 1 de proficiência na escala em Matemática. É possível observar que $68,1 \%$ dos alunos avaliados se encontram nos níveis 1 e abaixo de 1 , o que revela, segundo os parâmentos na $O C D E$, que esses alunos não possuem nível básico no conhecimento de Matemática. Esses alunos, conforme os resultados do PISA 2018, conseguem no mínimo interpretar e reconhecer, sem instruções diretas, como uma situação (simples) pode ser representada matematicamente. 
Nos níveis mais elevados, como exemplo o 4 ou acima, observa-se que aproximadamente $4,3 \%$ dos alunos brasileiros conseguiram obter essas pontuações. No nível 4, conforme os resultados do PISA 2018, diferentemente dos demais níveis mais baixos, os alunos são capazes, por exemplo, de selecionar e de integrar diferentes representações, incluindo representações simbólicas, relacionando-as diretamente com aspetos de situações da vida real.

Diante disso, nota-se que a situação dos alunos brasileiros em relação à Matemática mostra-se preocupante, principalmente pelo fato de apresentar uma porcentagem bastante elevada de alunos no nível abaixo de 1 (41\%), porcentagem essa bem superior à da OCDE, que é 9,1\% de proficiência na escala em Matemática. Nesse nível abaixo de 1, o PISA apresenta poucas tarefas que ajudam a descrevê-lo. No entanto, conforme OCDE (2019b), nesse nível é esperado que os alunos com proficiência menor que 358, equivalente ao nível abaixo de 1, consigam realizar algumas tarefas matemáticas diretas e fáceis. Isso inclui a leitura de apenas um valor em um gráfico ou em uma tabela, em que os rótulos do gráfico correspondem às palavras do estímulo e da questão, de maneira que os critérios de seleção estão claros e a relação entre o gráfico e os aspectos do contexto representado é evidente. Esses estudantes também conseguem executar cálculos aritméticos simples com números naturais, seguindo instruções claras e bem definidas (OCDE, 2019b).

Além do mais, para que possamos ter um resultado com mais detalhes sobre o desempenho dos alunos brasileiros no Pisa 2018, o próprio relatório de avaliação apresenta uma avaliação das diferenças regionais nos resultados da avaliação de Matemática dos alunos por nível de proficiência e também traz uma análise do desempenho geral por dependência administrativa (particular, federal, estadual e municipal). E, como o presente projeto será aplicado no município de Santa Cruz do Sul com professoras que lecionam em escolas públicas municipais, convém aqui apresentar o resultado apresentado pelas escolas públicas brasileiras na avaliação de Matemática, no caso desse projeto, escolas públicas municipais e o resultado apresentado pelos alunos brasileiros participantes no estado do Rio Grande do Sul.

No Gráfico 1 abaixo, mostramos o resultado apresentado pelos alunos brasileiros participantes no estado do Rio Grande do Sul, no qual podemos observar que apenas $18 \%$ dos alunos conseguiram alcançar o nível 3 de proficiência ou acima, na escala de proficiência em Matemática. No nível 2, nível que a OCDE estabelece como necessário para que o estudante possa exercer plenamente sua cidadania, considerado como o básico, observamos que apenas $22 \%$ dos alunos participantes alcançaram esse nível.

O Gráfico 1 mostra uma situação preocupante também para o estado do Rio Grande do Sul, pois revela que $60 \%$ dos alunos avaliados no estado encontram-se nos níveis 1 e abaixo de 1 , o que indica, segundo os parâmentos na $O C D E$, que esses alunos não possuem nível básico no conhecimento de Matemática.

Na pontuação média de proficiência em Matemática dos alunos brasileiros por dependência administrativa, o relatório de avaliação do Pisa 2018 apresentou a média de 314 pontos dos alunos das escolas públicas municipais e a média de 374 pontos dos alunos das escolas públicas estaduais participantes, conforme podemos observar na Tabela 2, abaixo, na qual ilustra-se uma diferença estatisticamente significativa, principalmente no caso das escolas municipais que apresentam pontuação de 70 pontos abaixo da média do Brasil, 384, esta que, por sua vez, está muito abaixo da média da OCDE, 489. 
Gráfico 1 - Resultado dos alunos brasileiros participantes no estado do Rio Grande do Sul na avaliação de Matemática por nível de proficiência.

\section{PORCENTAGEM DE ALUNOS POR NÍVEL DE PROFICIÊNCIA NO ESTADO DO RIO GRANDE DO SUL EM MATEMÁTICA - PISA 2018}

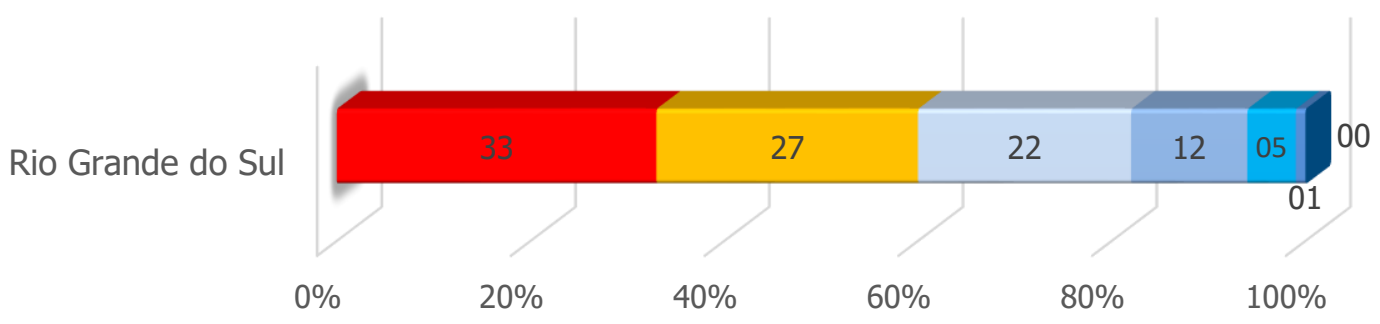

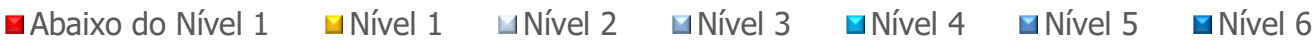

Fonte: Elaborado pela autora, com base em dados da OCDE e relatório do Brasil no PISA (2018).

Tabela 2 - Pontuação média de proficiência em Matemática dos alunos brasileiros por dependência administrativa (Municipal e Estadual) em relação a média do Brasil e da OCDE.

\begin{tabular}{|c|c|}
\hline DEPENDÊNCIAS ADMINISTRATIVAS & MÉDIA \\
\hline OCDE & 498 \\
\hline Brasil & 384 \\
\hline Estadual & 374 \\
\hline Municipal & 314 \\
\hline
\end{tabular}

Fonte: Elaborado pela autora, com base em dados da OCDE disponíveis no relatório PISA 2018.

Cabe aqui ressaltar que em cada edição do PISA é dada ênfase maior a uma das 3 (três) áreas avaliadas (Leitura, Matemática e Ciências), sempre em alternância, pois, segundo Relatório Brasil no (PISA 2018, 2019, p.15), "isso significa que os estudantes responderam a um maior número de itens no teste dessa área do conhecimento". Nesse caso, ressaltamos que, na última edição do Pisa no ano de 2018, o foco foi a leitura, na qual não estão disponíveis médias ou porcentagens sobre o desempenho dos alunos nas categorias de conteúdos Matemáticos, no entanto, tais porcentagens são apresentadas na edição de 2012, em que o foco principal foi a Matemática. Entre as quatro categorias de conteúdos matemáticos (variações e relações; espaço e forma; quantidade; incerteza e dados) que foram avaliados nessa edição, a área com desempenho mais crítico apresentada foi a de Espaço e Forma, na qual mostra que $70,9 \%$ dos alunos brasileiros avaliados estão no nível 1 e abaixo de 1 nessa categoria, conforme podemos observar no Gráfico 2, abaixo.

Esse resultado apresentado na categoria de conteúdos matemáticos, espaço e forma gera muita preocupação, pois, conforme o Pisa (2018, p. 103), essa categoria espaço e forma "envolve compreender a noção de perspectiva, a criação e a leitura de mapas, a transformação de formas (com e sem uso de tecnologias), a interpretação de vistas de cenas tridimensionais a partir de diferentes perspectivas, e a construção de representações de formas e, neste caso, esse resultado mostra que os alunos brasileiros avaliados não conseguiram desenvolver tais competências". No entanto, segundo a edição Pisa no ano de 2012, ao que se refere a essa categoria espaço e forma, especifica que,

Esta subárea compreende uma ampla gama de fenômenos que são encontrados em vários lugares e no mundo físico e visual: padrões; propriedade dos objetos; posição 
e orientação; representação dos objetos; codificação e decodificação de informação visual; interação dinâmica com formas reais, bem como com suas representações. A geometria pode ser considerada um fundamento para Espaço e Forma, mas essa categoria vai além do conteúdo tradicional da geometria, utilizando recursos de outras áreas da matemática, como visualização espacial, medida e álgebra. (OCDE, 2012, p. 33).

Gráfico 2 - Resultado brasileiro na categoria de conteúdo, espaço e forma, na disciplina de matemática por nível no PISA 2012.

\section{RESULTADO BRASILEIRO NA CATEGORIA DE CONTEÚDO MATEMÁTICOS ESPAÇO E FORMA - PISA 2012}

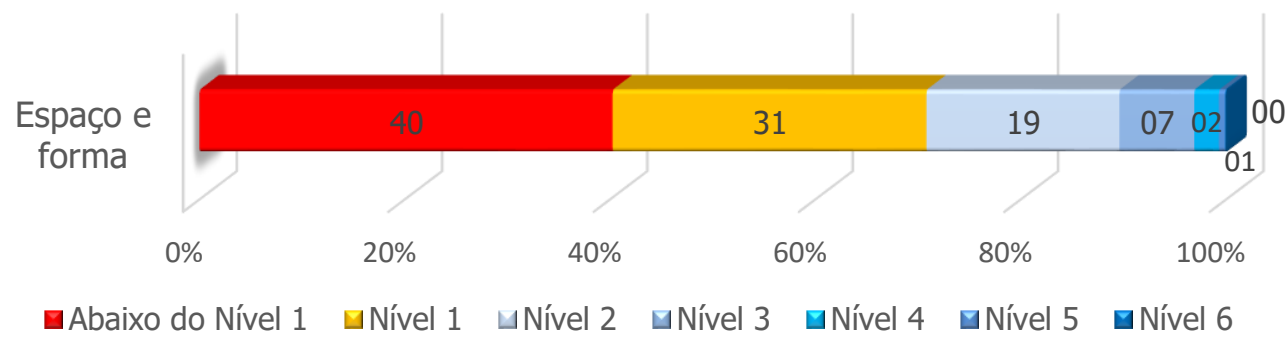

Fonte: Elaborado pela autora, com base em dados da OCDE disponíveis no relatório nacional PISA 2012, resultados brasileiros. Disponível em:

<https://download.inep.gov.br/acoes_internacionais/pisa/resultados/2014/relatorio_nacional_pisa_2012_resul tados_brasileiros.pdf>. Acesso em: 28 jan. 2021.

No portal do Ministério da Educação e do Desporto (MEC) foi publicado que a média em Matemática está entre as menores do Pisa e descreve que a categoria de conteúdo com os maiores valores no índice de desempenho foi a de espaço e forma pois,

[...] esta subárea da avaliação de matemática envolve uma diversidade de propriedades encontradas em vários lugares no mundo físico e visual. Trabalha-se, por exemplo, com as propriedades das figuras geométricas, como o perímetro ou a área, e as características das figuras espaciais entre outras. A interação dinâmica com formas reais, bem como com suas representações, mostrou-se um conteúdo mais difícil e trabalhoso para os estudantes. (BRASIL. MEC, 2019).

No entanto, como a categoria espaço e forma é considerada, segundo o MEC, a de menor valor no índice de desempenho no Pisa, em virtude de os alunos brasileiros apresentarem baixo desempenho na disciplina de Matemática e média baixa, neste caso, o Gráfico 4, acima, mostra perfeitamente esse baixo desempenho, pois o Brasil apresentou aproximadamente $18,8 \%$, dos alunos participantes que conseguiram atingir o nível 2 e apenas $10,4 \%$ dos alunos conseguiram obter pontuação no nível 3 ou acima desse nível na categoria de conteúdos matemáticos espaço e forma. Contudo, essa situação revela-se preocupante, principalmente pelo fato de mostrar que $40,3 \%$ dos alunos brasileiros avaliados ficaram no nível abaixo de 1 , que são considerados pela OCDE, alunos que não possuem nível básico no conhecimento de Matemática. Além do mais, no relatório anterior, o Pisa 2015, esse desempenho baixo não foi muito diferente, pois o mesmo relata que o conteúdo espaço e forma apresentou, na época, desempenho mais baixo dos alunos brasileiros em itens que trabalham "as propriedades das figuras geométricas, ou as características das figuras espaciais" (PISA 2015, p. 157), o que demonstra que esse desempenho baixo vem se agravando a cada ano. 


\section{GEOMETRIA NOS ANOS FINAIS DO ENSINO FUNDAMENTAL}

Após analisar as porcentagens apresentadas pela avaliação de Matemática do Brasil no Pisa e verificar o baixo desempenho que os alunos brasileiros vêm apresentando na categoria de conteúdo Espaço e Forma da disciplina de Matemática, logo vem em mente a seguinte questão: será que esses conteúdos, espaço e forma, especificamente a geometria, estão sendo contemplados no currículo? E a equipe docente tem a formação adequada para ensiná-los?

Em busca de respostas a essas perguntas achamos necessário verificar o que esclarecem os Parâmetros Nacional Curriculares (PCNs) (BRASIL, 1998) e a Base Nacional Comum Curricular (BNCC) $^{7}$ (BRASIL, 2017) acerca dessa categoria e desse conteúdo. Ressaltamos que, nos PCNs (1998), na categoria de conteúdos, aparece a denominação Espaço e Forma, a qual evidencia a geometria clássica, axiomática e suas relações internas, e ainda "pressupõe que o professor de Matemática explore situações em que sejam necessárias algumas construções geométricas com régua e compasso, como visualização e aplicação de propriedades das figuras, além da construção de outras relações" (PCN, 1998, p. 51). Porém, cabe aqui destacar que não é apresentada qualquer ênfase às aplicações ou relações da geometria com o ambiente, espaço e convívio social dos alunos.

No entanto, no documento desenvolvido para orientar o ensino no Brasil, a atual BNCC, promulgada pelo Ministério da Educação (MEC) no ano de 2017, especifica, na área da Matemática dos anos finais do Ensino Fundamental, que os conteúdos relativos à geometria clássica continuam presentes, porém é dada ênfase à geometria das transformações e à utilização das diferentes representações de um mesmo objeto matemático na resolução de problemas em vários contextos, como os socioambientais e da vida cotidiana, tendo em vista que elas têm um papel decisivo na aprendizagem dos alunos. Destaca, ainda, a importância do docente na seleção de experiências de sala de aula para que a aprendizagem seja aproveitada ao máximo.

Além do mais, na área da Matemática dos anos finais do Ensino Fundamental na BNCC (2017), consta que as decisões pedagógicas devem estar orientadas para o desenvolvimento de "competências e habilidades" (BRASIL, 2017, p. 15). Essa orientação advém de uma conformidade com "uma tendência internacional "[...] que garante um desenvolvimento direcionado e sistemático das habilidades e competências necessárias para a matemática em todas as áreas do conteúdo e em todos os anos da formação básica" (JOHNSON, 2016, p.4). Essa tendência internacional, provém de países que obtiveram melhor desempenho no Programa Internacional de Avaliação de Estudantes de 2018 (Pisa 2018), pelo fato de serem países que contam com diretrizes nacionais mais eficientes na elaboração de seus currículos e referenciam o desenvolvimento de competências, como é o exemplo da Coréia e da Finlândia. Esse tipo de abordagem vem ocorrendo,

[...] desde as décadas finais do século XX e ao longo deste início do século XXI, o foco no desenvolvimento de competências tem orientado a maioria dos Estados e Municípios brasileiros e diferentes países na construção de seus currículos. É esse também o enfoque adotado nas avaliações internacionais da Organização para a

\footnotetext{
7 A Base Nacional Comum Curricular (BNCC) é um documento de caráter normativo que define o conjunto orgânico e progressivo de aprendizagens essenciais que todos os alunos devem desenvolver ao longo das etapas e modalidades da Educação Básica, de modo que tenham assegurados seus direitos de aprendizagem e desenvolvimento, em conformidade com o que preceitua o Plano Nacional de Educação (PNE). Este documento normativo aplica-se exclusivamente à educação escolar, tal como a define o $\S 1^{\circ}$ do artigo $1^{\circ}$ da Lei de Diretrizes e Bases da Educação Nacional (LDB, lei nº 9394/1996), e está orientado pelos princípios éticos, políticos e estéticos que visam à formação humana integral e à construção de uma sociedade justa, democrática e inclusiva, como fundamentado nas Diretrizes Curriculares Nacionais de Educação Básica (DCN). (BRASIL, 2017, p. 7)
} 
Cooperação e Desenvolvimento Econômico (OCDE), que coordena o Programa Internacional de Avaliação de Alunos (Pisa, na sigla em inglês), e da Organização das Nações Unidas para a Educação, a Ciência e a Cultura (Unesco, na sigla em inglês), que instituiu o Laboratório Latino-americano de Avaliação da Qualidade da Educação para a América Latina (LLECE, na sigla em espanhol). Ao adotar esse enfoque, a BNCC indica que as decisões pedagógicas devem estar orientadas para o desenvolvimento de competências. (BRASIL, 2017, p.13).

Dessa forma, no âmbito da BNCC, a ideia de competência é utilizada no sentido da aplicação dos conhecimentos escolares, entendido de maneira ampla, como, por exemplo, conceitos, procedimentos, valores e atitudes. Dessa maneira, ser competente representa ser capaz de, ao se defrontar com uma situação ou um problema, conseguir estabelecer conexões e utilizar o conhecimento construído.

No Brasil, o autor matemático D’Ambrosio (2004) descreve que o ensino da Matemática deve estar baseado na relação com a vida cotidiana, contextualizado, tornando o sujeito capaz de apreender, compreender, explicar e lidar criticamente com situações novas e com a realidade que o cerca. Nesse sentido, almeja-se que o ensino seja voltado para proporcionar um maior domínio e capacidade cognitiva ao estudante para fazer uso social de seu conhecimento matemático, dentro e fora da escola.

Isso nos remete à ideia de que os alunos precisam compreender que os conhecimentos aprendidos durante as aulas são aplicáveis em situações do nosso cotidiano. E, para que isso ocorra, acreditamos que é necessário em sala de aula desenvolver o pensamento crítico e a criatividade nas resoluções de problemas.

Em virtude disso, o ensino de geometria, no caso da categoria Espaço e Forma, se torna tão primordial, visto que, na nova BNCC (Brasil, 2017) em relação a geometria aos anos finais do Ensino Fundamental, é destacado que,

[...] a Geometria envolve o estudo de um amplo conjunto de conceitos e procedimentos necessários para resolver problemas do mundo físico e de diferentes áreas do conhecimento. Assim, nessa unidade temática, estudar posição e deslocamentos no espaço, formas e relações entre elementos de figuras planas e espaciais pode desenvolver o pensamento geométrico dos alunos. Esse pensamento é necessário para investigar propriedades, fazer conjecturas e produzir argumentos geométricos convincentes. É importante, também, considerar o aspecto funcional que deve estar presente no estudo da Geometria: as transformações geométricas, sobretudo as simetrias. As ideias matemáticas fundamentais associadas a essa temática são, principalmente, construção, representação e interdependência. (BRASIL, 2017, p. 271).

No entanto, o conteúdo de geometria é descrito de forma que seja desenvolvido a partir de representações de localização e/ou de movimentação de objetos no plano e no espaço. De certa forma, há uma necessidade de dar continuidade, dar uma consistência sistemática e fortalecer as aprendizagens anteriores, especificamente em relação à compreensão de características e propriedades das figuras geométricas, tais como as construções geométricas com a utilização de materiais manipuláveis, bem como tecnologias e também as aplicações no cotidiano e em outras áreas do conhecimento, construindo uma aprendizagem mais articulada e significativa.

Desse modo, nos permite dizer que a Matemática está muito mais presente no nosso cotidiano do que imaginamos, pois para onde quer que olhemos, é possível observar formas, pois convivemos diariamente com a Geometria, sendo que fazer uso de situações do cotidiano como forma de se 
construir significados daquilo que se aprende é fundamental, visto que a aprendizagem geométrica é imensamente essencial para o desenvolvimento do aluno. De acordo com Lorenzato (1995), a Geometria faz parte sim do nosso cotidiano e, mesmo sem querer, estamos lidando com a ideia de paralelismo, perpendicularismo, congruência, semelhança, proporcionalidade, comprimento, área, volume, simetria e muitas outras situações. Dessa perspectiva, segundo os Parâmetros Curriculares Nacionais (PCN) (Brasil, 1998), é evidenciada a importância de se trabalhar com o aluno a geometria, pois "os conceitos geométricos constituem parte importante do currículo de Matemática no ensino fundamental, porque, por meio deles, o aluno desenvolve um tipo especial de pensamento que the permite compreender, descrever e representar, de forma organizada, o mundo em que vive" (BRASIL, 1998, p. 51).

Diante disso, mesmo sabendo que no ensino a categoria Espaço e Forma, ou seja, a geometria é tão primordial que Almouloud et al. (2004) afirmam que, Espaço e Forma é uma das categorias de conteúdos da Matemática que menos recebe atenção nas aulas e justifica esse fato, em virtude das dificuldades identificadas no "nosso sistema educativo, que define a política da educação com recomendações e orientações gerais sobre os métodos, os conteúdos e o saber fazer, deixando para cada escola definir os conteúdos que julga importantes para a formação de seus alunos, o que faz com que a geometria seja frequentemente esquecida" (ALMOULOUD et al., 2004, p. 99). Neste caso, é apontado que esse descaso com a geometria também está vinculada à precariedade do ensino da geometria relacionada à formação docente,

[...] podemos apontar, em relação à formação dos professores, que esta é muito precária quando se trata de geometria, pois os cursos de formação inicial não contribuem para que façam uma reflexão mais profunda a respeito do ensino e da aprendizagem dessa área da matemática. Por sua vez, a formação continuada não atende ainda aos objetivos esperados em relação à geometria. Assim, a maioria dos professores do ensino fundamental e do ensino médio não está preparada para trabalhar segundo as recomendações e orientações didáticas e pedagógicas dos PCN. (ALMOULOUD et al., 2004, loc. cit.)

Em virtude disso, cabe aqui ressaltar que o território brasileiro conta com uma grande dimensão de sua extensão territorial e se torna difícil definir e implementar um currículo que seja nacional e único a todos os estabelecimentos de ensino. Essa situação é reconhecida pela própria da Lei de Diretrizes e Bases (LDB no 9394/96) que atribui aos Sistemas de Ensino autonomia para definirem as suas próprias propostas curriculares, desde que em consonância com as determinações da esfera federal para o efeito. Nesse caso, no que tange à autonomia da escola para elaborar sua proposta pedagógica, a lei descreve o seguinte,

Art. 12. Os estabelecimentos de ensino, respeitadas as normas comuns e as do seu sistema de ensino, terão a incumbência de: I - elaborar e executar sua proposta pedagógica;

Art. 13. Os docentes incumbir-se-ão de: I - participar da elaboração da proposta pedagógica do estabelecimento de ensino;

Art. 15. Os sistemas de ensino assegurarão às unidades escolares públicas de educação básica que os integram progressivos graus de autonomia pedagógica e administrativa e de gestão financeira, observadas as normas gerais de direito financeiro público. (BRASIL, 1996, p. 5-6).

Diante dessa descrição, frente à necessidade de pôr em vigor os currículos, os sistemas de ensino foram elaborando as suas próprias propostas e orientações curriculares. Em vista disso, logo vem em nossa mente o questionamento sobre como pôde a Geometria com tamanha importância para o 
ensino e aprendizagem do aluno ser vista atualmente como um conhecimento que está sendo tão pouco valorizado, chegando ao ponto de ser até deixada de lado por algumas escolas e/ou docentes?

Nesse caso, observamos que a escola atualmente é quem desempenha o papel fundamental de transmitir o conhecimento, sendo que, nas últimas décadas, é possível perceber o abandono gradual da Geometria. Decorre que, com a promulgação da Lei de Diretrizes e Bases (LDB no 5692/71), o descaso com a geometria no Brasil se tornou ainda mais evidente nas escolas públicas, pelo fato de as mesmas passarem a ter mais autonomia para selecionar o conteúdo curricular. Contudo, diversos docentes, inseguros em trabalhar com a Geometria, usufruíram desse benefício de decisão e acabaram deixando de lado ou abordando a geometria mais no final do ano letivo, o que, em muitos casos, pela falta de tempo, os impede de cumprir o que é proposto nos planos de ensino, fazendo com que os docentes optem, assim, por deixar a Geometria para o ano letivo seguinte, como afirma Pavanello (1989), em sua dissertação de mestrado, intitulada como "o abandono do ensino de Geometria: uma visão histórica", quando observou que,

[...] docentes não dominavam nem o conteúdo (alguns confessavam não haver jamais estudado ou fizeram de modo insatisfatório) nem a maneira de desenvolvê-lo com seus alunos. Dentre aqueles que incluiam geometria entre os tópicos a serem desenvolvidos em sala de aula, muitos afirmavam que, por falta de tempo, não conseguiam chegar a abordá-la nem parcialmente. Quando indagados sobre a época do ano reservada para este assunto, respondiam, invariavelmente, ser o último bismestre, ou na melhor das hipóteses, o último trimestre do ano letivo, o que parecia indicar que, conscientemente ou não, a falta de tempo estava sendo usada como desculpa para a não realização do trabalho com geometria. (PAVANELLO, 1989, p. 6)

Apesar disso, Lorenzato (1995) ressalta que são inúmeras as causas para esse descaso e abandono da geometria nas escolas brasileiras, apontando duas dessas causas que estão diretamente ligadas a sala de aula. Na primeira, reforça "que muitos professores não detêm os conhecimentos geométricos necessários para realização de suas práticas pedagógicas" (LORENZATO, 2015, p. 3) e, acima de tudo, considera que "o professor que não conhece Geometria também não conhece o poder, a beleza e a importância que ela possui para a formação do futuro cidadão, então, tudo indica que, para esses professores, o dilema é tentar ensinar Geometria sem conhecê-la ou então não ensiná-la" (LORENZATO, 2015, p. 3). A segunda causa da omissão geométrica "deve-se à exagerada importância que, entre nós, desempenha o livro didático, quer devido à má formação de nossos professores, quer devido à estafante jornada de trabalho a que estão submetidos" (LORENZATO, 2015, p. 3).

Apesar disso, é possível perceber que, inúmeras vezes, o esforço ou entusiasmo do docente com a disciplina de Matemática não é compartilhado pelos alunos, o que pode estar contribuindo também para um baixo rendimento dos mesmos, assim como destaca Tashima e Silva $(2008$, p.6).

O fraco desempenho em geometria por parte dos alunos é resultado, muitas vezes, da utilização de práticas que não atendem às suas expectativas, dentre outras coisas, do abismo existente entre o modo como os professores e alunos percebem a matemática. $O$ professor imagina que seus alunos terão o mesmo prazer que ele tem ao lidar com a Matemática. No entanto, o aluno não consegue vê-la do mesmo modo, e por isso não a compreende. (TASHIMA e SILVA, 2008, p.6)

No entanto, Pavanello (1989) investigou a relação entre a falência do ensino de geometria e o despreparo do professor, e afirma que, "embora este ensino venha se mostrado problemático - não é só no Brasil, como também no resto do mundo - de modo que vem sendo objeto de muito debate e de muitas pesquisas, estas, me parece, se concentram no 'como' ensinar este conteúdo" 
(PAVANELLO, 1989, p. 9). Segundo a autora, os pontos mais comuns para o declínio da Geometria na escola são os problemas com a formação do docente, omissão da Geometria nos livros didáticos e as lacunas deixadas pelo Movimento da Matemática Moderna (MMM). Dessa forma, Pavanello (1989) ainda reforça que esses problemas vêm persistindo até as novas gerações e, tais causas, certamente contribuem no fracasso, no descaso, no abandono da geometria e, consequentemente, no baixo desempenho dos alunos que estão sendo afetados por não aprenderem geometria, conforme reforça Pereira (2001).

Todas essas questões e outras subsequentes, durante esses anos, geraram polêmicas e colaboram para evidenciar a ausência da Geometria nas escolas, cujos, os reflexos, hoje interferem nos saberes dos professores em atuação. Portanto, pode-se afirmar que os conteúdos que não foram aprendidos pelos professores também não serão sequer transmitidos, quanto mais interagidos - originando um círculo vicioso - que afeta, por conseguinte, gerações de alunos que não aprendem Geometria. (PEREIRA, 2001, p.7).

Apesar de tudo, percebemos também que esse abandono do ensino da Geometria não aconteceu pelo fato de a Matemática ter se desenvolvido e a Geometria considerada desnecessária ou menos importante. O fato é que, historicamente, desde o início do século XX, de acordo com Pavanello (1993), o Brasil ainda era um país agrícola, e a maioria das pessoas não tinham acesso à educação básica e muitas eram consideradas analfabetas na época. O ensino de Matemática na escola apresentava somente algumas noções de Geometria, direcionado apenas para as atividades comerciais práticas. Somente após o início da década de 60, com o surgimento no Brasil do movimento conhecido como Matemática Moderna, visando adaptar o ensino da Matemática a novos ramos, foi que surgiram, então, os primeiros livros didáticos com a inserção de figuras geométricas, intersecção de figuras, representada através da Teoria dos Conjuntos e gerando enfoque sob transformações. A abordagem ocorria de forma mais intuitiva e não havia muita preocupação com a construção. Porém, como a grande maioria dos docentes de Matemática na época não dominava muito bem tais conceitos, ocorreu que muitos desses docentes acabaram deixando de ensiná-los para dar mais ênfase à Álgebra. Então, no ano de 1971, a Lei de Diretrizes e Bases do Ensino de $1^{\circ}$ e $2^{\circ}$ Graus chegou para sancionar essa situação e possibilitar que cada docente pudesse optar pelo seu programa de ensino, em conformidade com as necessidades dos seus alunos. Segundo Pavanello (1993),

[...] existem fortes motivos para a inquietação dos professores com o abandono da Geometria e sua insistência em melhorar seus conhecimentos em relação a ela. A ausência do ensino de Geometria e a ênfase no da álgebra pode estar prejudicando a formação dos alunos por privá-los da possibilidade do desenvolvimento integral dos processos de pensamento necessários à resolução de problemas matemáticos. (PAVANELLO, 1993, p. 16).

De fato, quanto mais pesquisamos, mais percebemos que é possível encontrar diversos motivos para não deixar que a Geometria caia no descaso total, visto que ela desenvolve o pensamento visual, favorece a análise de relações e de fatos e promove o desenvolvimento de um pensamento mais autônomo e mais crítico. Porém, sabemos que nem sempre isso acontece, o que não justifica esse abandono ou descaso, e sim, acredita-se ser possível investir em novas pesquisas sobre metodologias que sejam mais pertinentes para a abordagem desse conteúdo e que possa destinar mais atenção ao melhoramento na capacitação e formação dos docentes, para que se tenha, conforme salienta Pavanello (1993), como consequência, a qualidade no ensino de Geometria. 
Sendo assim, é primordial desenvolver na escola materiais que favoreçam o uso da geometria e também formar docentes para o uso das mesmas, pois, segundo Lorenzatto (1995, p. 5),

[...] a Geometria está por toda parte", desde antes de Cristo, mas é preciso conseguir enxergá-la... mesmo não querendo, lidamos em nosso cotidiano com as ideias de paralelismo, perpendicularismo, congruência, semelhança, proporcionalidade, medição (comprimento, área, volume), simetria: seja pelo visual (formas), seja pelo uso no lazer, na profissão, na comunicação oral, cotidianamente estamos envolvidos com a Geometria.

Entretanto, ainda persistem grandes desafios para a Educação Básica, pois como observamos, o desempenho dos alunos do Ensino Fundamental na disciplina de Matemática está relativamente baixo. Para o ano de 2021, na nova avaliação do Pisa, a Matemática será a principal disciplina cobrada e irá "verificar, entre outras competências, a capacidade de interpretar problemas matemáticos em vários contextos do mundo real" (BRASIL, 2019).

O quadro conceptual de Matemática do PISA $2021^{8}$, disponível pela OCDE, define os fundamentos teóricos da avaliação da Matemática e relata que, nessa avaliação, o conhecimento das categorias de conteúdo ganharão especial atenção, como, por exemplo, "a identificação de aproximações geométricas como um ponto focal da categoria de conteúdo de Espaço e forma indicando a necessidade de os alunos serem capazes utilizar o seu conhecimento sobre fenômenos tradicionais de espaço e forma" (OCDE, 2018, p.25, tradução da pesquisadora).

Dessa forma, não somente nas avaliações de desempenho, mas no cotidiano, no ensino e na aprendizagem de nossos alunos a aprendizagem da geometria se faz necessária ao desenvolvimento do mesmo e é fundamental, no entanto, os resultados obtidos nessas avaliações não são nada agradáveis. Segundo Passos (2000), essas avaliações de desempenho realizadas, principalmente as que mostram o desenvolvimento da geometria em sala de aula, tem revelado que,

[...] as avaliações sobre o desempenho dos estudantes em Matemática e também em geometria, realizado por órgãos responsáveis pela educação dos Estados Brasileiros, ou diretamente pelo Ministério de Educação (MEC), tem demonstrado uma ausência de conexão entre as propostas de ensino elaboradas pelos órgãos governamentais e os resultados constatados na escola. (PASSOS, 2000, p.41).

\section{CONSIDERAÇÕES FINAIS}

Esses resultados representam indicativos que nos permitem deduzir que não é de hoje que obstáculos na Educação Matemática ocorrem na prática, nos anos finais do Ensino Fundamental. Essas são apenas algumas informações que, de certo modo, nos fazem refletir sobre a necessidade de apoio aos docentes que ensinam Matemática nos anos finais do Ensino Fundamental, bem como seus alunos. Como vimos, o ensino de geometria vem sendo muitas vezes deixado de lado e o desempenho dos alunos brasileiros apresenta-se abaixo do nível básico exigido, o que nos permite entender um pouco sobre a importância do problema proposto nessa pesquisa, o estudo de geometria no Ensino Fundamental, problema sistêmico, que merece muito a nossa atenção, pois não é somente um problema citado pelos docentes participantes desta pesquisa de forma isolada. Isto é, não é um problema de apenas um docente, de apenas um aluno, de apenas uma escola, de apenas um

8 Quadro conceptual de Matemática do PISA 2021, disponível em: <https://pisa2021maths.oecd.org/files/PISA\%202021\%20Mathematics\%20Framework\%20Draft.pdf>. Acesso em: 29 jan. 2021. 
município, de apenas um estado, de apenas um país, mas, sim, é um problema típico do mundo em que vivemos.

\section{REFERÊNCIAS}

ALMOULOUD, Saldo Ag. et. al. A geometria no ensino fundamental: reflexões sobre uma experiência de formação envolvendo professores e alunos. Revista Brasileira de Educação. Set/Out/Nov/Dez $2004 \quad$ n²7. Disponível em: <https://www.scielo.br/j/rbedu/a/xzRGKxDRJ6XS4ZXxLnBTkFL/?format=pdf\&lang=pt>. Acesso em: 11 nov. 2021.

BRASIL. Ministério da Educação. Avaliação Internacional: Média em Matemática está entre as menores do Pisa. Brasília: MEC, 2018. Disponível em: <http://portal.mec.gov.br/ultimasnoticias/222-537011943/42771-media-em-mateatica-esta-entre-as-menores-do-pisa>. Acesso em: 26 fev. 2021.

Instituto Nacional de Estudos e Pesquisas Educacionais Anísio Teixeira (INEP). Relatório Brasil no PISA 2018 (versão preliminar). (2019). Brasília-DF Inep/MEC. Disponível em: <https://download.inep.gov.br/acoes_internacionais/pisa/documentos/2019/relatorio_PISA_2018_p reliminar.pdf>. Acesso em: 28 jan. 2021.

Ministério da Educação. Matemática será a principal disciplina cobrada no Pisa 2021. Brasília: MEC, 2018. Disponível em: <http://portal.mec.gov.br/component/tags/tag/33571>. Acesso em: 11 nov. 2021.

. Instituto Nacional de Estudos e Pesquisas Educacionais Anísio Teixeira (INEP). Relatório Nacional PISA 2012: resultados brasileiros. São Paulo: Fundação Santillana/Organização para a Cooperação e Desenvolvimento Econômico (OCDE). Disponível em: $<$ https://download.inep.gov.br/acoes_internacionais/pisa/resultados/2014/relatorio_nacional_pisa_ 2012_resultados_brasileiros.pdf>. Acesso em: 26 fev. 2021.

Base Nacional Comum Curricular (BNCC). Educação é a Base. Brasília, MEC/CONSED/UNDIME, p. 600, 2017. Disponível em: <http://basenacionalcomum.mec.gov.br/images/BNCC_EI_EF_110518_versaofinal_site.pdf>. Acesso em: 10 nov. 2021.

Parâmetros Curriculares Nacionais (PCNs). Matemática. Terceiro e quarto ciclos do Ensino Fundamental. Brasília: MEC/SEF, 1998.

Ministério da Educação. Lei de Diretrizes e Bases da Educação Nacional. Lei n. 9.394/96. Disponível em: <http://www.planalto.gov.br/ccivil_03/Leis/L9394.htm>. Acesso em: 10 nov. 2021.

CRUZ, P.; MONTEIRO, L. (Org.) Anuário Brasileiro da Educação Básica 2019. São Paulo: Editora Moderna, 2019.

JONHSON, Susan Barton. Análise da Base Nacional Comum Curricular de Matemática. ACARA. 2016. Disponível em: <https://movimentopelabase.org.br/wp-content/uploads/2016/08/5.2Matema\%CC\%81tica_Ana\%CC\%81lise-da-ACARA.pdf>. Acesso em: 10 nov. 2021.

LORENZATO, Sérgio. Como aprendemos e ansinamos geometria. In: LORENZATO, S. Aprender e ensinar geometria. Campinas, SP: Mercado das Letras, 2015. Série Educação Matemática. 
Por que não ensinar Geometria? Educação Matemática em RevistaSBEM, Blumenau-SC, no 4, p. 03-20, $1^{0}$ sem. 1995.

PASSOS, Carmen Lucia Brancaglion. Representações e prática pedagógica: a geometria na sala de aula. 2000. 348p. Tese (Doutorado em Educação) Unicamp, Campinas, SP, 2000.

PAVANELLO, Regina Maria. 0 abandono do ensino de Geometria no Brasil: causas e consequências. In Zetetiké, v. 1, n. 1, 1993.

. O abandono do ensino de geometria: uma abordagem histórica. 1989. $195 f$. Dissertação (Mestrado em Educação) - UNICAMP, Campinas.

PEREIRA, Maria Regina de Oliveira. A geometria escolar: uma análise dos estudos sobre o abandono de seu ensino. Dissertação de Mestrado em Educação Matemática. São Paulo: PUC, 2001.

PORTUGAL. Ministério da Educação. PISA 2012: Portugal, primeiros resultados. Lisboa, 2013. Disponível em: <https://www.dgeec.mec.pt/np4/246/\%7B\$clientServletPath\%7D/?newsId=371\&fileName=PISA_P rimeiros_Resultados_PORTUGAL.pdf>. Acesso em: 25 fev. 2021.

TASHIMA, M. M. SILVA, A. L. da. As lacunas no ensino-aprendizagem da geometria. 2007. Disponível em: <http://www.gestaoescolar.diaadia.pr.gov.br/arquivos/File/producoes_pde/artigo_m arina_massaco_tashima.pdf>. Acesso em: 11 nov. 2021.

Submissão: 12/11/2021

Aceito: 10/12/2021 